\title{
TO QUESTION OF DETERMINING DESIGN PARAMETERS OF WORKING BODY OF ROTARY CHOPPER OF TOPS
}

\author{
Marat Kalimullin ${ }^{1}$, Dinar Ismagilov ${ }^{2}$, Rinat Abdrakhmanov ${ }^{2}$, Marat Salimzyanov ${ }^{3}$, Rafkat Latypov ${ }^{4}$ \\ ${ }^{1}$ Kazan State Agrarian University, Russia; ${ }^{2}$ Tatar Institute of Personnel Development of Agribusiness, \\ Russia; ${ }^{3}$ Izhevsk State Agricultural Academy, Russia; ${ }^{4}$ South Ural State Agrarian University, Russia \\ marat-kmn@yandex.ru,dinar3009544@mail.ru,rinatkadyrovic@mail.ru, salimmar@mail.ru
}

\begin{abstract}
Potato production in the Russian Federation and in many countries of the world is important. In the public sector, potatoes are cultivated on farms, personal and subsidiary plots. In connection with the transition to market relations, the area for planting potatoes has sharply decreased, and as a result, the production of potato harvesting equipment. Therefore, an acute question arose of the further creation and production of the simplest potato harvesting equipment and the improvement of their new working bodies. Pre-harvest removal chopping tops occupies an important place in the technology of potato cultivation. During operation, it was noted that rotary machines have a number of disadvantages caused by the imperfection of the rotor design, its kinematic modes, insufficient balance and reliability. In order to eliminate these shortcomings, a rotary topper with a vertical axis of rotation was designed and manufactured. To justify the design and operational parameters, theoretical studies of the process of interaction of the working element of the chopper with the tops of root crops were carried out, as a result of which the main patterns characterizing the working element were identified. In particular, dependence was obtained that allows to determine the cross-sectional diameter of the working element, which takes into account both the design parameters of the developed grinder and the properties of the tops. After calculating the obtained dependence, it was determined that for the operation of the unit with a minimum energy consumption, the diameter of the working element should be $6 \mathrm{~mm}$. Such a working element cuts the tops in compliance with all agricultural requirements. Field experiments conducted later confirmed the obtained value, which indicates the reliability of the results.
\end{abstract}

Keywords: diameter, work item, energy, moment of inertia, topper.

\section{Introduction}

The quality of harvesting largely depends on the technologies used and the agricultural machinery used. Potato is one of the most important crops cultivated in the world. It is used for food, technical and feed purposes. Due to the closure of most agricultural machinery factories at the end of the 20th century and the saturation of the market with imported equipment in the Russian Federation, an important scientific and practical task was the development and manufacture of import-substituting units that perform the process in compliance with all agrotechnical requirements. To facilitate the work of potato harvesters and to increase the quantity and quality of the crop, potato tops must be removed before harvesting. There are several ways to remove potato tops: chemical, mechanical and combined. In the middle of the 20th century, in countries such as Belgium and the Netherlands, topping up was carried out with heat, for which burners using liquid fuel or propane were used. Using this method, the tops were completely removed, but the organic matter of the upper layers of the soil was also burned, which in fact exposes the soil to destruction. This led to the abandonment of the thermal method of removing potato tops. In the United States and England, the chemical method of removal has become widespread, in which the tops are processed by desiccation, that is, by chemical means. The chemical method leads to the slow death of the tops and the intensive outflow of nutrients into the tubers, which does not lead to a significant decrease in yield due to top removal. Effectively apply desiccant is possible only in stable dry weather. Due to the need for spraying up to two to three weeks before harvesting, in some areas of Russia due to the short harvest time, the use of this method is very difficult. Currently, the world is trying to minimize the use of the chemical method of grinding potato tops in accordance with the requirements of environmental protection and to obtain an environmentally friendly crop. Therefore, the most suitable for removing potato tops is the mechanical method.

After analyzing the operation of the top choppers with the horizontal rotation axis UBD-3, BD4U, RSK 2000, KS-3000 and others, we can say about the good quality of the work, but they have a significant drawback - heavy loads on the working body, which as a result leads to frequent breakdown of hammers and violation of the dynamic balance of agricultural machinery. To reduce the number of breakdowns, it is often necessary to check the technical condition of the working units and 
parts, the reliability of their fasteners, which leads to a sharp decrease in the efficiency or performance of such crushers.

At present, along with direct combining, a complex for separate cleaning is used for cleaning: a top-harvesting machine and a tuber-harvesting machine. It is obvious that in this case two tractors will be working on the field. As a result, the energy capacity of the harvesting technological process will increase. More effective harvesting is reached by usage of harvesting combines. However, these machines are very expensive and not all farmers can buy them [1-5].

\section{Materials and methods}

In order to increase the efficiency and more fully load of an energy-saturated tractor of the third class, it is proposed to use in a single unit a harvesting machine and a haulm chopper (Figure 1) [6-8].

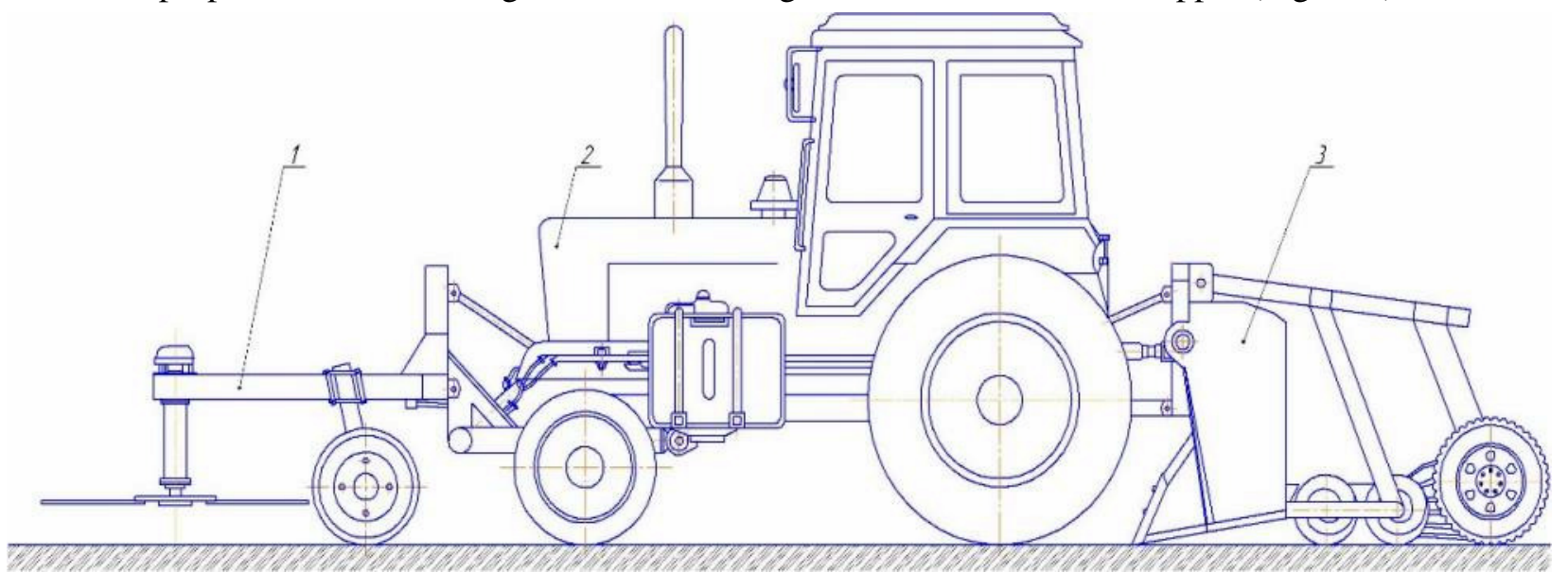

Fig. 1. Unit for simultaneous grinding of tops and harvesting:

1 - haulm chopper, 2 - tractor, 3 - harvesting machine

The weeder is hanged on the rear hinge of the tractor and its active working parts drive is performed by a power take-off shaft.

The haulm chopper is hanged on the front hinge of the tractor and the working parts are rotating with the help of hydraulic motors. It allows two machines with different functions, different kinematical and technological parameters to conduct their work.

The chopper device consists of a frame, a linkage mechanism and support wheels. The support wheels are mounted to adjust the cutting height by moving up or down. Hydromotors are mounted on the frame. The lower part of the hydraulic motor is rigidly connected to the crosspiece of the working body, which is made in the form of the working elements fixed to the crosspiece.

In addition, one of the peculiarities of the suggested haulm chopper is usage of rubber-fabric operating elements (Figure 2) that allow to weed the tops softly.

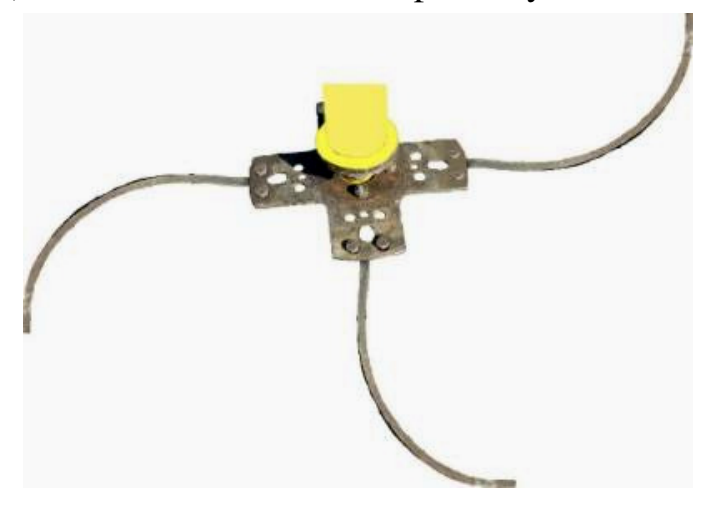

Fig. 2. Rubber-fabric operating element of rotational haulm chopper

To conduct the research, the haulm remover experimental prototype with the new operating elements was produced. During the experiments, when removing the tops, the chopper carried out the process using a rubber working element. 
The experiments were carried out in accordance with the chart. In this case, the rotation speed of the flexible working element and its diameter varied over a wide range. The studies were carried out by the screening method, that is, such parameters were selected that were further investigated at different speeds of the machine and tractor unit and various locations of the flexible working body on the rotor.

Before experimental studies, it is necessary to determine the method of planting and the height of the ridges, the distance between the bushes in the row, the size of the butt and main row spacing, the number of stems in the bushes, the width of the crown of the bush, the height of the stems, the length of straightened stems, the condition of the tops, the mass of tops, and the degree of weediness of the studied plot.

Experimental studies to determine the optimal diameter of the flexible working element were carried out at a constant speed of translational movement of the unit $\mathrm{V}=3.0 \mathrm{~m} \cdot \mathrm{s}^{-1}$, and a variable rotational speed of the rotary organ $n=1000-2000 \mathrm{~min}-1$.

\section{Results and discussion}

To determine the diameter of the flexible working element, theoretical studies of the process of its interaction with the tops were carried out.

The energy needed for stalk chopping can be presented as the following formula [9]:

$$
E_{P}=(\alpha+\beta \cdot d) \cdot S,
$$

where $\alpha$ and $\beta$-coefficients depending on material and stalk structure;

$d$ - working element diameter, m;

$S$ - stalk sectional area, $\mathrm{m}^{2}$.

This energy depends on the stalk part. With the change of the chopping level from top to the root, the energy is growing. That fact proves our assumption that the energy is different for different parts of the stalk.

According to the agrotechnical requirements [10-14], it is necessary to remove tops from roots as high as possible. This can be done by choosing certain technological parameters so that the rotating speed of working elements can be calculated on the basis of the most unfavorable cases and conditions. It means that the rotating speed should be counted on the maximal energy value $E_{p}$.

Taking into consideration the law of energy conservation, during the chopping the top removal operating element spends its part or all of the kinetic energy. It should be mentioned that it is not appropriate, even unacceptable, to lower energy costs through reduction of the working element rotating speed. When the rotating speed is lowering, the interaction time between the working element and stalk is increasing. And, consequently, the stalk part reaction time, stalk reaction zone and the amount of energy going to the stalk is increasing.

The working element kinetic energy can be defined by means of the formula:

$$
W_{K}=\frac{I \cdot \omega^{2}}{2},
$$

where $I-$ moment of inertia of the working element, $\mathrm{kg} \times \mathrm{m}^{2}$.

The moment of inertia of the working element, when rotating around an axis passing through the mass center, can be defined by means of formula:

$$
I_{0}=\frac{1}{12} \cdot M \cdot l^{2},
$$

where $M$ - rod mass, $\mathrm{kg}$;

$l-$ rod length, $\mathrm{m}$.

When the axis of rotation does not coincide with the mass center, the following formula is used:

$$
I=I_{0}+M \cdot a^{2},
$$

where $a$-distance from axis of rotation to the mass center, $\mathrm{m}$. 
In our case, the length of the working element is $l=L-l_{0}$ and its mass center is at a distance of $a=\left(L+l_{0}\right) / 2$ from the axis of rotation. The mass of the rotating element can be calculated by formula:

$$
M=2 \cdot \frac{\pi \cdot d^{2}}{4} \cdot \rho \cdot\left(L-l_{0}\right)=\frac{\pi \cdot d^{2}}{2} \cdot \rho \cdot\left(L-l_{0}\right),
$$

where $d$-diameter of the working element, $\mathrm{m}$;

$\rho$ - density of the material the operating element is made of, $\mathrm{kg} \cdot \mathrm{m}^{-3}$.

Following the formula (4), we have:

$$
I=\frac{1}{12} \cdot M \cdot\left(L-l_{0}\right)^{2}+M \cdot\left(\frac{L+l_{0}}{2}\right)^{2},
$$

or after simplification we have:

$$
I=\frac{M}{3} \cdot\left(L^{2}+L \cdot l_{0}+l_{0}^{2}\right)
$$

Then the kinetic energy equates:

$$
W_{K}=\frac{M}{6} \cdot\left(L^{2}+L \cdot l_{0}+l_{0}^{2}\right) \cdot \omega^{2}=\frac{\pi \cdot d^{2}}{12} \cdot \rho \cdot \omega^{2} \cdot\left(L^{3}-l_{0}^{3}\right) .
$$

We can see that both $E_{p}$ and $W_{K}$ depend on the working element diameter $d$, that is, the less is $d$, the less is the chopping energy. The kinetic energy is also decreasing $W_{K}$. If the kinetic energy is small, it can be not enough for chopping, which is why the following condition must be fulfilled:

$$
W_{K} \geq E_{P} \text {. }
$$

The dependence of $E_{p}$ and $W_{K}$ on $d$ is presented in Figure 3 .

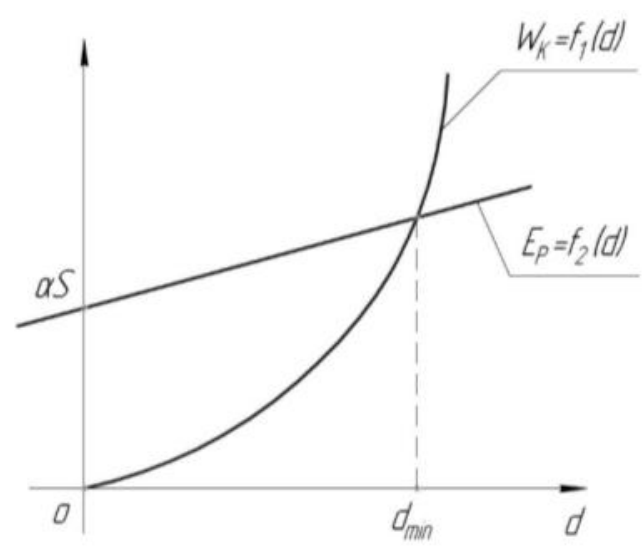

Fig. 3. Schematic graphs of functions $E_{P}=f(d)$ and $W_{K}=f(d)$ change

$E_{p}$ depends on the parameter $d$ linearly (a direct line on the graph), and $W_{K}$ - parabolically (parabola on the graph). The graph shows that, when $d<d_{\min }$, the kinetic energy is not enough for stalk chopping. Consequently, we need to define the least diameter of the operating element.

Let us define the parameter $d_{\min }$ from the condition:

$$
W_{K}=E_{P} .
$$

Applying formulas (1) and (7) to formula (9), we have:

$$
\frac{\pi}{12} \cdot \rho \cdot \omega^{2} \cdot\left(L-l_{0}\right) \cdot\left(L^{2}+L \cdot l_{0}+l_{0}^{2}\right) \cdot d^{2}=(\alpha+\beta \cdot d) \cdot S,
$$

or after making some substitutions, we have the following square equation:

$$
A \cdot d^{2}-B \cdot d-C=0
$$

where $\quad A=\frac{\pi}{12} \cdot \rho \cdot \omega^{2} \cdot\left(L-l_{0}\right) \cdot\left(L^{2}+L \cdot l_{0}+l_{0}^{2}\right)$; 


$$
\begin{aligned}
& B=\beta S ; \\
& C=\alpha S .
\end{aligned}
$$

The solution to this square equation will be the following formula:

$$
d_{\min }=\frac{B+\sqrt{B^{2}+4 \cdot A \cdot C}}{2 \cdot A} .
$$

As a result of substituting the values of the variables, we obtain the following expression:

$d_{\min }=\frac{\beta \cdot S+\sqrt{(\beta \cdot S)^{2}+\frac{\pi}{3} \cdot \rho \cdot \omega^{2} \cdot\left(L-l_{0}\right) \cdot\left(L^{2}+L \cdot l_{0}+l_{0}^{2}\right) \cdot \alpha \cdot S}}{\frac{\pi}{6} \cdot \rho \cdot \omega^{2} \cdot\left(L-l_{0}\right) \cdot\left(L^{2}+L \cdot l_{0}+l_{0}^{2}\right)}$.

We can see that the bigger are the stalk parameters $\alpha, \beta, S$, the bigger are the parameters $B$ and $C$, and, consequently, the bigger is $d_{\min }$. The working element parameter points influence in an opposite way: the bigger are the parameters $\rho, \omega, L$, the bigger is $A$, and the less is $d_{\min }$.

As a result of substituting the values of the variables, we obtain the following expression:

$$
\begin{aligned}
& d_{\min }=\frac{69620.25 \cdot 0.05+\sqrt{(69620.25 \cdot 0.05)^{2}+\pi / 3 \cdot 1050 \cdot 157.08^{2} \cdot(0.7-0.2)}}{\frac{\pi}{6} \cdot 1050 \cdot 157.08^{2} \cdot(0.7-0.2) \cdot\left(0.7^{2}+0.7 \cdot 0.2+0.2^{2}\right)} \\
& \frac{\left(0.7^{2}+0.7 \cdot 0.2+0.2^{2}\right) \cdot 5860.806 \cdot 0.05}{2}=0.006074 \approx 0.006 \mathrm{~m} .
\end{aligned}
$$

Having calculated this expression, we obtain that the diameter of the flexible working element is $6 \mathrm{~mm}$.

The experimental tests of the developed haulm chopper were carried on the experimental field of the Kazan State Agrarian University. It should be noted that preliminary theoretical research presented the possibility of reducing the labor costs for experimental studies.

A graphical interpretation of the result of the experiment to determine the diameter of the working element is shown in Figure 4.

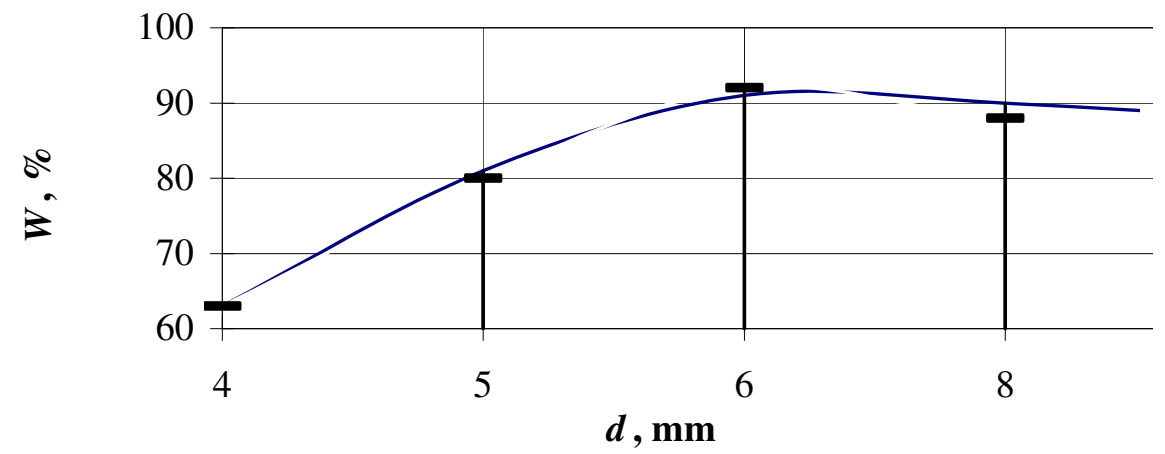

Fig. 4. Dependence of the completeness of grinding the tops $W$ on the value of the cross-sectional diameter of the flexible working element $d$

Figure 4 shows that the diameter that provides the maximum completeness of removing the tops is $6 \mathrm{~mm}$, which confirms the theoretical calculations. When using a working element with a large diameter, the quality of the process of removing the tops slightly deteriorates and increases the metal consumption, and hence, the energy intensity of the work. And if to use a cable with a smaller diameter, then metal and energy are saved, but the quality of top removal is significantly impaired.

It also provided the execution of agrotechnical requirements, that is, top removal both according to the top removal quality and root damage degree. As a result, when the removal degree was up to $92 \%$, root damage was not observed. 


\section{Conclusions}

The results of preliminary studies of the unit, consisting of a tractor, a harvesting machine and the developed top chopper, showed the possibility of reducing labor costs, energy consumption of the technological process and direct operating costs by $30 \%$ in comparison with the combine harvesting technology under certain conditions.

The results of mathematical modeling confirmed that there will be enough energy for chopping the tops, if the diameter of the working element is $6 \mathrm{~mm}$. The experimental studies have confirmed our assumptions and theoretical studies on the possibility of reducing trauma of root crops, when removing the sugar beet tops by the proposed top picker.

\section{References}

[1] Byshov N.V., Borychev S.N., Simdyankin A.A., Kolotov A.S., Kolupaev S.V.,Kiryushin I.N., Uspenskii I.A., Shemyakin A.V., Yukhin I.A. Modern view on potato production Polythematic network electronic scientific journal of the Kuban State Agrarian University № 128, 2017, pp. 146-153.

[2] Maximov L.M., Maximov P.L., Maximov L.L. A new way of separating potato tubers from soil and tops. The rural machine operator. No. 3. 2009, pp. 6-7.

[3] Kalimullin M., Abdrakhmanov R., Andreev R., Semenov A., Vasilyev O., Zaitsev P., Arkhipov S. Improvement of potato cultivation technology IOP Conference Series: Earth and Environmental Science, 2019, P. 012017.

[4] Pervushin V.F., Ivanov AG, Salimzyanov MZ. Modeling of the grinder of potato tops. Mechanization and electrification of agriculture. No. 6. 2010, pp. 2-3.

[5] / Pervushin VF, Ivanov AG, Salimzyanov MZ. Determination of the rotational speed of the rotor of the chopper of potato tops. Mechanization and electrification of agriculture. No. 9. 2010, pp. 45.

[6] Ismagilov D.M., Abdrakhmanov R.K., Kalimullin M.N., Ziatdinov R.R. The results of experiments with the rotational haulm chopper BIR-2 Achievements of science and technology in the agro-industrial complex. No. 12. 2017, pp. 61-64.

[7] Uglanov MB, Bachurin AN, Byshov DN, Abramov Yu.N. The study of the modernized bd-4m botodrobitel with hinged knives. Political Mathematical Network Electronic Scientific Journal of the Kuban State Agrarian University. 2017. No. 128. 2017, pp. 200-213.

[8] Bulgariev G.G., Kalimullin M.N., Abdrakhmanov R.K., Khamitov R.R. Kinematic of the toothed rotational operating element's movement Bulletin of Kazan State Agrarian University. No. 3 (41). 2016, pp. 68-71.

[9] Kalimullin M.N., Abdrakhmanov R.K., Arkhipov S.M. Rotary haulm chopper parameters development and substantiation for root and tuber crops International Journal of Applied Engineering Research Volume 10, Number 10, 2015, pp. 25691-25697.

[10] Karpov M.V., Shardina G. E., Zhizdyuk A. A. Study of the effectiveness and economic evaluation of the application of the developed potato planting machine Agricultural scientific journal No.4. (LLC Amirit, Saratov), 2018, pp. 41-47.

[11] Rembalovich G.K., Byshov N.V., Borychev S.N., Uspenskii I.A., Ryazanov N.A., Beznosyuk R.V., Bulatov E.P. Innovative solutions harvesting and transport technological processes and technical means in potato Agricultural machinery and technologies No.1, 2013, pp. 23-25.

[12] Shardina G.E., Karpov M.V. Justification kinematical parameters spoon-belt apparatus are planted Scientific Review (Saratov, LLC “APEX-94”) No. 4. 2011, 117 p.

[13] Tubolev S.S. et al. Machine technologies and equipment for potato production (Moscow: Agrospas), 2010, $316 \mathrm{p}$.

[14] Semenov A. V., Novikov A.M. The effectiveness of seed germination in the cultivation of early potatoes Bulletin of the Chuvash State Agricultural Academy No.2 (5), 2018, pp. 22-26. 